\title{
Reduced neurobehavioral impairment from sleep deprivation in older adults: contribution of adenosinergic mechanisms
}

\author{
Hans-Peter Landolt ${ }^{1,2,3}{ }^{*}$, Julia V. Rétey ${ }^{1}$ and Martin Adam ${ }^{1}$ \\ 1 Institute of Pharmacology and Toxicology, University of Zürich, Zürich, Switzerland \\ 2 Zürich Center for Integrative Human Physiology, University of Zürich, Zürich, Switzerland \\ ${ }^{3}$ Neuroscience Center Zürich, Eidgenössische Technische Hochschule Zürich, University of Zürich, Zürich, Switzerland
}

\section{Edited by:}

Géraldine Rauchs, GIP Cyceron,

France

Reviewed by:

Jonathan P. Wisor, Washington State Universtiy, USA

Andreas Bauer, Research Center

Juelich, Germany

*Correspondence:

Hans-Peter Landolt, Institute of

Pharmacology and Toxicology,

University of Zürich,

Winterthurerstrasse 190, 8057 Zürich, Switzerland.

e-mail: landolt@pharma.uzh.ch
A night without sleep is followed by enhanced sleepiness, increased low-frequency activity in the waking EEG, and reduced vigilant attention. The magnitude of these changes is highly variable among healthy individuals. Findings in young men of low and high subjective caffeine sensitivity suggest that adenosinergic mechanisms contribute to inter-individual differences in sleep deprivation-induced changes in EEG theta activity, as well as optimal performance on the psychomotor vigilance task (PVT). In comparison to young subjects, healthy adults of older age typically feel less sleepy after sleep deprivation, and show fewer response lapses, and faster reaction times on the PVT, especially in the morning after the night without sleep. We hypothesized that age-related changes in adenosine signal transmission underlie reduced vulnerability to sleep deprivation in older individuals. To test this hypothesis, the combined effects of prolonged wakefulness and the adenosine receptor antagonist, caffeine, on an antero-posterior power gradient in EEG theta activity and PVT performance were analyzed in healthy older and caffeine-insensitive and -sensitive young men. The results show that age-related differences in sleep loss-induced changes in brain rhythmic activity and neurobehavioral functions are mirrored in young individuals of low and high sensitivity to the stimulant effects of caffeine. Moreover, the effects of sleep deprivation and caffeine on regional theta power and vigilant attention are inversely correlated across older and young age groups. Genetic variants of the adenosine $A_{2 A}$ receptor gene contribute to individual differences in neurobehavioral performance in rested and sleep deprived state, and modulate the actions of caffeine in wakefulness and sleep. Based upon this evidence, we propose that age-related differences in $A_{2 A}$ receptor-mediated signal transduction could be involved in age-related changes in the vulnerability to acute sleep deprivation.

Keywords: aging, electroencephalogram, attention, $A_{1}$ receptors, $A_{2 A}$ receptors, ADORA2A

\section{INTRODUCTION}

Sleep deprivation affects subjective and objective measures of alertness, attention, and vigilance, as well as higher cognitive capabilities such as perception, memory, and executive functions (Goel et al., 2009). There exist, however, considerable and systematic inter-individual differences in the susceptibility to the lack of sleep. Among young healthy people, these differences are robust, trait-like, and possibly related to genetically determined, neurobiological differences in the physiological processes underlying the homeostatic and circadian regulation of wakefulness and sleep (Landolt, 2008a; Dijk and Archer, 2010; Van Dongen et al., 2012). Evidence from pharmacological and microdialysis studies in animals and humans strongly suggests the involvement of the neuromodulator adenosine and adenosine receptors in the effects of sleep deprivation (Ticho and Radulovacki, 1991; Schwierin et al., 1996; Porkka-Heiskanen et al., 2000; Landolt et al., 2004; Wyatt et al., 2004; Christie et al., 2008). Adenosinergic mechanisms may, thus, contribute to individual susceptibility or resistance to performance impairment as a consequence of sleep loss.

To investigate this hypothesis, the combined effects of prolonged wakefulness and the adenosine receptor antagonist, caffeine, on sustained vigilant attention were studied in two groups of young healthy men with low and high (as evidenced by experiencing sleep disturbances after caffeine consumption in the afternoon) subjective caffeine sensitivity (Rétey et al., 2006). Performance on the psychomotor vigilance task (PVT), a reliable measure of sustained vigilant attention (Lim and Dinges, 2008), was assessed at regular intervals before, during, and after one night without sleep. After 11 and $23 \mathrm{~h}$ of prolonged wakefulness, subjects received $200 \mathrm{mg}$ caffeine and placebo in double-blind, cross-over manner. This dose of caffeine equals roughly the caffeine content in a double-espresso. Sleep deprivation impaired PVT performance more in caffeine-sensitive individuals than in caffeine-insensitive individuals. This difference was counteracted 
by caffeine. These findings suggest that adenosinergic mechanisms contribute to individual differences in waking-induced impairment of neurobehavioral performance.

Normal human aging is associated with profound changes in sleep-wake behavior. Older people may rise early without feeling refreshed, feel sleepy during the day, take naps, go to bed early, have difficulty falling asleep, show superficial sleep with little or no slow-wave sleep (SWS), and exhibit frequent sleep interruptions and early morning awakenings. These alterations in the quality of wakefulness and sleep may be secondary to health problems, or reflect changes and/or disruptions in homeostatic and circadian sleep-wake regulatory mechanisms (Dijk et al., 2010). The detailed characteristics of sleep and sleep disorders in older age and their possible underlying causes have been reviewed elsewhere (e.g., Bliwise and Carrier, 2012). Interestingly, convergent recent insights from animal experiments as well as controlled studies in healthy humans consistently show that older people may be less sleepy during the daytime and better tolerate sleep deprivation when compared to young adults (animal experiments: Wigren et al., 2009; Hasan et al., 2012; human studies: Bonnet and Rosa, 1987; Münch et al., 2004; Philip et al., 2004; Urrila et al., 2004; Adam et al., 2006; Blatter et al., 2006; Duffy et al., 2009; Dijk et al., 2010). Some authors suggested that an altered response of the adenosinergic system contributes to these age-related changes in the behavioral repercussions of prolonged wakefulness (Murillo-Rodriguez et al., 2004; Rytkönen et al., 2010). This hypothesis, however, has not been tested in humans.

In this article, we will address the question whether adenosinergic mechanisms may contribute to reduced neurobehavioral impairment from sleep deprivation in healthy older adults. First, the current understanding of how adenosine and adenosine receptors are involved in sleep-wake regulation will be recapitulated. Then, evidence will be summarized suggesting that the competitive adenosine receptor antagonist, caffeine, attenuates the physiological consequences of sleep loss on functional brain oscillations in non-rapid-eye-movement (NREM) sleep and wakefulness, as well as on neurobehavioral performance. Next, empirical data will be reviewed and presented which demonstrate that older age not only modulates functional characteristics of adenosine and its receptors, but also the repercussions of caffeine on sleep and waking EEG, as well as vigilant attention after sleep deprivation. Finally, a few possible research strategies will be proposed that could be pursued to investigate in more detail the roles for adenosine and adenosine receptors in reduced vulnerability of older adults to impaired neurobehavioral performance after the lack of sleep.

\section{THE NEUROMODULATOR ADENOSINE CONTRIBUTES TO THE PHYSIOLOGICAL CONSEQUENCES OF SLEEP DEPRIVATION}

The effects of the prior history of wakefulness and sleep on functional characteristics of recovery sleep and the quality of wakefulness have been conceptualized as sleep homeostasis in the two-process model of sleep regulation (Borbély, 1980, 1982). The duration of SWS and the amount of computer-detected EEG slow-wave activity (SWA) in NREM sleep are considered the principle markers of the sleep-wake dependent, homeostatic aspect of sleep regulation. Biochemically, one or more endogenous "sleep substances" may accumulate during wakefulness and dissipate during sleep, yet the biochemical "substrates" of sleep homeostasis remain poorly understood. It is widely accepted, however, that adenosine, nitric oxide, prostaglandin $\mathrm{D}_{2}$, tumor necrosis factor, interleukin-1, growth-hormone-releasing hormone, and brainderived neurotrophic factor are important chemicals that may be primarily involved in mediating the consequences of prolonged wakefulness. Especially with respect to adenosine, compelling and converging evidence has accumulated over the past two decades to support a role for this neuromodulator and its receptors in sleep homeostasis in animals and humans (Krueger et al., 2008; Landolt, 2008b; Porkka-Heiskanen and Kalinchuk, 2011).

The formation of adenosine in the brain changes in activitydependent manner, and different mechanisms contribute to the appearance of adenosine in extra-cellular space. Increased energy demand during wakefulness leads to the break-down of energyrich adenine nucleosides such as adenosine-tri-phosphate (ATP). Adenosine is formed in neurons by $5^{\prime}$-nucleotidase and transported through plasma and intra-cellular membranes by specialized transporters, including sodium-driven concentrative (CNT) and equilibrative nucleoside transporters (ENT; Figure 1A). The CNTs use energy to move adenosine into the cell, whereas the ENTs transport adenosine according to the extra-cellular/intra-cellular concentration gradient. Elevated intra-cellular adenosine concentrations following increased utilization of ATP in conditions of high energy demand lead to release of adenosine. In addition, extra-cellular adenosine is also formed through ecto-nucleotidasemediated hydrolysis of ATP. Release of ATP from synaptic vesicles occurs along with several neurotransmitters, including the major excitatory neurotransmitter glutamate (Haydon and Carmignoto, 2006). Finally, ATP and glutamate are also released from astrocytes by a recently established process referred to as gliotransmission. The ATP may either be hydrolyzed to adenosine or activate purinergic receptors such $\mathrm{P}_{2} \mathrm{X}_{7}$ receptors and affect sleep directly or indirectly, yet independently from adenosine (Krueger et al., 2008, 2010).

Molecular genetic manipulations in mice suggest that glial cells provide a significant source of extra-cellular adenosine in the brain (Haydon and Carmignoto, 2006). Mice expressing a dominantnegative ( $\mathrm{dn}$ ) SNARE domain in astrocytes have reduced gliotransmission (Pascual et al., 2005). A recent study in these mice suggests that adenosine derived from astrocytes is importantly involved in the homeostatic regulation of sleep pressure (Halassa et al., 2009). Both transgenic and wild-type mice spent similar proportions of the light-phase (i.e., the major sleep phase in mice) in NREM sleep, rapid-eye-movement (REM) sleep and wakefulness. By contrast, sleep pressure (or sleep intensity) as reflected in SWS/SWA was significantly reduced when dnSNARE was expressed exclusively in astrocytes. The differences were specific to NREM sleep and not present in REM sleep and wakefulness, and most pronounced in the 0.5 - to $1.5-\mathrm{Hz}$ range. Importantly, dnSNARE expression attenuated the sleep deprivation-induced increase in SWA in NREM sleep, particularly in the low-frequency range and in hours 2-4 of recovery sleep. Moreover, performance on a novel object recognition task was unimpaired after sleep deprivation in dnSNARE mice, while it was dramatically reduced in wild-type animals. Taken together, these data are consistent with an important role 


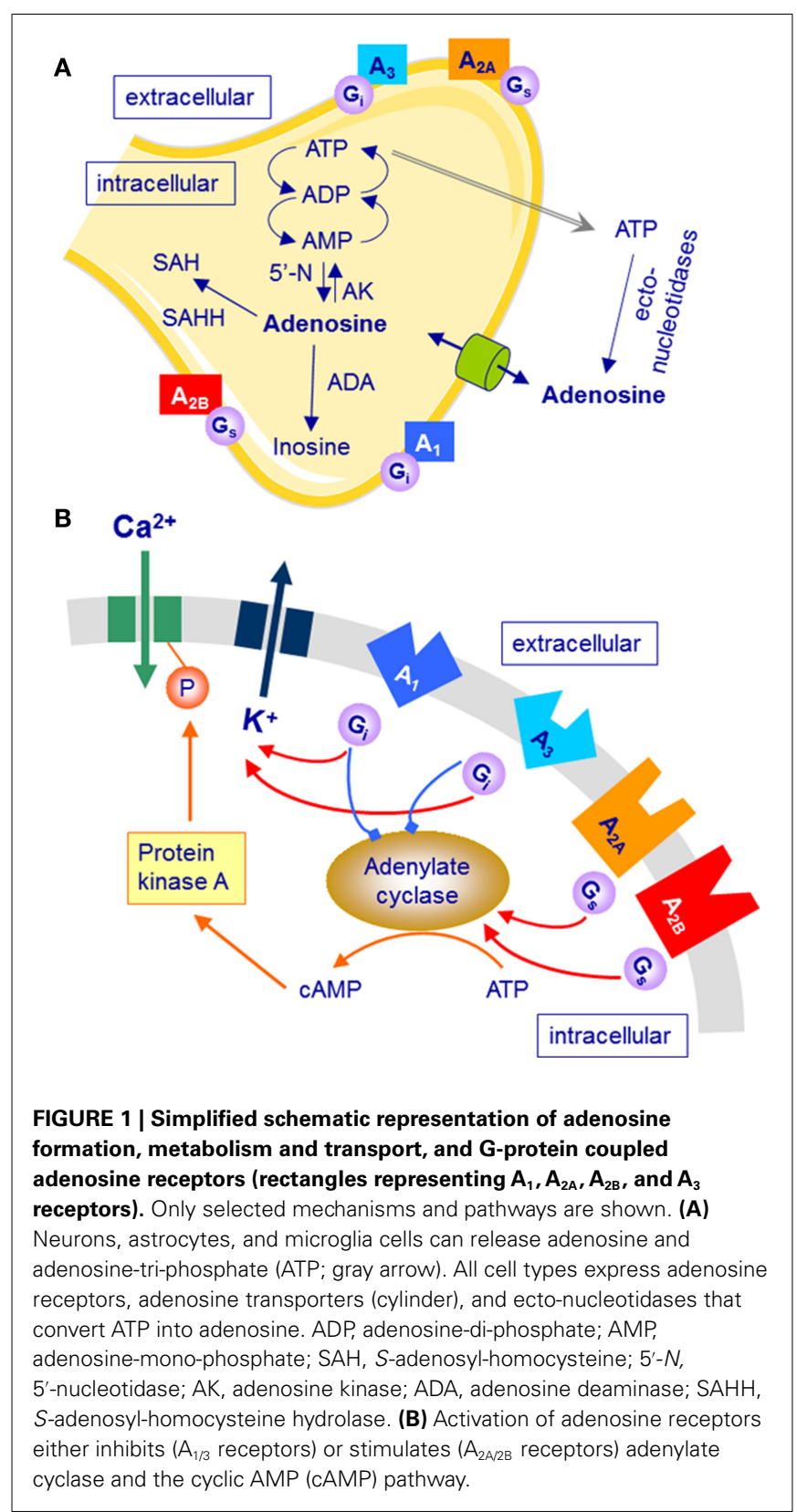

for glia-dependent adenosine in regulating established markers of sleep homeostasis in mice.

Clearance of extra-cellular adenosine mostly occurs through the non-concentrative nucleoside transporters (Fredholm et al., 2005). The main intra-cellular metabolic pathways of adenosine are the formation of adenosine-mono-phosphate by adenosine kinase (AK), and the irreversible break-down to inosine by adenosine deaminase (ADA). Ecto-ADA also catalyzes the extra-cellular deamination of adenosine. Mainly due to the high activity of AK, baseline levels of extra-cellular adenosine usually remain low. The action of ADA, which appears to be more abundantly expressed in astrocytes than in neurons (Fredholm et al., 2005), may be particularly important when large amounts of adenosine have to be cleared. Both, a genetic variant of ADA in humans (Bachmann et al., 2012) and pharmacological inhibition of $\mathrm{AK}$ in rodents increase SWS/SWA (Okada et al., 2003; Palchykova et al., 2010).

\section{ADENOSINE $A_{1}$ AND $A_{2 A}$ RECEPTORS MEDIATE EFFECTS OF ADENOSINE IN SLEEP-WAKE REGULATION}

The cellular effects of adenosine are mediated via four subtypes of G-protein coupled adenosine receptors: $A_{1}, A_{2 A}, A_{2 B}$, and $A_{3}$ receptors. In vitro studies indicate that physiological concentrations of endogenous adenosine can activate $A_{1}, A_{2 A}$, as well as $\mathrm{A}_{3}$ receptors. Nevertheless, it is widely accepted that the highaffinity $A_{1}$ and $A_{2 A}$ receptors are primarily involved in mediating the effects of adenosine on vigilance and sleep, at least in humans (Sebastiao and Ribeiro, 2009).

\section{ADENOSINE $A_{1}$ RECEPTORS AND THE EFFECTS OF PROLONGED WAKEFULNESS}

The stimulation of $A_{1}$ receptors opens several types of $\mathrm{K}^{+}$channels, inhibits adenylate cyclase through activation of $\mathrm{G}_{i}$ proteins and inactivates transient voltage-dependent $\mathrm{Ca}^{2+}$-channels (Figure 1B). The $A_{1}$ receptor is ubiquitously but not homogenously expressed in the central nervous system (Bauer and Ishiwata, 2009). In vivo imaging with the selective $\mathrm{A}_{1}$ receptor antagonist, ${ }^{18} \mathrm{~F}$-CPFPX, recently developed for positron emission tomography (PET) revealed highest receptor occupancy in striatum and thalamus, as well as temporo-parietal and occipital cortex. Because of the inhibition of excitatory neurotransmission after pre- and post-synaptic $A_{1}$ receptor activation and the wide-spread distribution of this receptor subtype in the brain, it has been generally assumed that adenosine affects sleep-wake regulation primarily via this receptor subtype. Pharmacological and genetic studies in rats and mice, as well as molecular imaging in humans, partly support this assumption (Schwierin et al., 1996; Thakkar et al., 2003; Elmenhorst et al., 2007, 2009; Bjorness et al., 2009). For example, inducible knock-out of neuronal adenosine $\mathrm{A}_{1}$ receptors reduced SWA (3.0-4.5 Hz range) in NREM sleep under baseline conditions, and attenuated the homeostatically regulated rise in SWA after sleep restriction (Bjorness et al., 2009). These knock-out mice also showed impaired working memory when sleep was curtailed. Moreover, prolonged wakefulness appears to up-regulate $\mathrm{A}_{1}$ receptor binding in cortical and subcortical brain regions in animals and humans (Elmenhorst et al., 2007, 2009). Taken together, these data indicate a role for adenosine $\mathrm{A}_{1}$ receptors in mediating the functional consequences of sleep deprivation.

\section{ADENOSINE $A_{2 A}$ RECEPTORS AND THE EFFECTS OF PROLONGED WAKEFULNESS}

Stimulation of $\mathrm{A}_{2 \mathrm{~A}}$ receptors increases adenylate cyclase activity through activation of $\mathrm{G}_{\mathrm{s}}$ (or $\mathrm{G}_{\mathrm{olf}}$ in striatum) proteins, induces the formation of inositol phosphates, and activates protein kinase A (Figure 1B). Compared to the $A_{1}$ receptor, this adenosine receptor subtype is less widely distributed in the brain (Bauer and Ishiwata, 2009). Highest expression in the human central nervous system was found in basal ganglia (particularly in putamen and caudate nucleus) and thalamus. Recent studies in rodents, including experiments in knock-out mice, suggest that also $A_{2 A}$ receptors contribute to the effects of adenosine on sleep. Local administration of the selective $A_{2 A}$ receptor agonist, CGS21680, to the 
subarachnoid space adjacent to basal forebrain and lateral preoptic area increased $c$-fos expression in the ventro-lateral pre-optic (VLPO) area and promoted NREM sleep (Scammell et al., 2001). Direct activation of sleep-promoting VLPO neurons upon stimulation of $\mathrm{A}_{2 \mathrm{~A}}$ receptors could underlie this effect (Gallopin et al., 2005). Interestingly, preliminary data showed that mice with $A_{2 A}$ receptor loss-of-function may have reduced sleep and attenuated responses to sleep deprivation (Hayaishi et al., 2004).

Taken together, both adenosine $\mathrm{A}_{1}$ and $\mathrm{A}_{2 \mathrm{~A}}$ receptor subtypes probably mediate functional effects of adenosine after sleep deprivation, and these effects appear to be site- and receptor-dependent.

\section{CAFFEINE ATTENUATES FUNCTIONAL CONSEQUENCES OF SLEEP LOSS}

Caffeine is the most widely consumed stimulant in the world. In the micro-molar plasma concentrations reached after moderate consumption, caffeine acts as a non-selective, competitive antagonist at both $\mathrm{A}_{1}$ and $\mathrm{A}_{2 \mathrm{~A}}$ receptors. It may be important to note, however, that caffeine fails to promote wakefulness in mice lacking functional $A_{2 A}$ receptors, whereas this effect is preserved in $A_{1}$ receptor-deficient mice (Huang et al., 2005). Other effects of caffeine can also be obtained in vitro, including inhibition of phosphodiesterase, blockade of $\mathrm{GABA}_{\mathrm{A}}$ receptors, and $\mathrm{Ca}^{2+}$ release. For these actions, however, drug doses are needed that are more than 100 times higher than those for adenosine receptor antagonism and toxic in humans (Fredholm, 1995).

\section{CAFFEINE ATTENUATES EEG MARKERS OF PROLONGED WAKEFULNESS IN NREM SLEEP}

Acute administration of caffeine in doses equivalent to one to two cups of coffee (100-200 mg) prolongs sleep latency, impairs sleep efficiency, and reduces the duration of SWS (for review, see Landolt, 2008b). Moreover, the stimulant induces changes in the NREM sleep EEG, which are opposite to those of sleep deprivation. Specifically, spectral power within the slow-wave range $(\sim 1-$ $2.5 \mathrm{~Hz}$ ) was decreased, whereas power in the spindle frequency range $(\sim 12-15 \mathrm{~Hz})$ was increased. It is remarkable that these EEG alterations were still observed at night, even when caffeine was administered in the morning to either rested or sleep deprived subjects (Landolt et al., 1995, 2004). Supporting an important role for adenosine and adenosine receptors in the effects of sleep deprivation, these caffeine-induced EEG changes in NREM sleep in part mimicked the consequences of a nap in the afternoon, which induces a physiological reduction in NREM sleep pressure (Werth et al., 1996).

Regional EEG analyses revealed that SWA in NREM sleep is largest over frontal cortical areas, especially after sleep deprivation (Cajochen et al., 1999; Tinguely et al., 2006). These observations indicate that frontal parts of the cortex reflect the homeostatic process of sleep-wake regulation more sensitively than other cortical regions. To study a possible contribution of adenosinergic mechanisms to these regional differences, the interaction of sleep deprivation and caffeine on the spatial distribution of lowfrequency $(<1 \mathrm{~Hz})$ EEG power in NREM sleep was investigated in young, self-rated caffeine-insensitive and -sensitive men (Rétey et al., 2006). It was found that the two groups responded differently to these challenges of sleep-wake regulation. Most interestingly, the changes induced by caffeine were opposite to the effects of prolonged wakefulness, and the efficacy of the stimulant was negatively correlated to the effects of sleep deprivation.

\section{CAFFEINE ATTENUATES EEG MARKERS OF SLEEP DEPRIVATION IN WAKEFULNESS}

During prolonged wakefulness, caffeine attenuated the increase of subjective sleepiness and EEG theta activity after sleep deprivation (Landolt et al., 2004). Spectral power in the theta band $(\sim 5-9 \mathrm{~Hz})$ of the waking EEG is considered an objective measure of sleep pressure. Similar to NREM sleep, theta power increased more in an anterior EEG derivation than in a posterior derivation, primarily in self-rated caffeine-sensitive individuals (Rétey et al., 2006). Moreover, caffeine attenuated the waking-induced frontooccipital power gradient, and the effects of sleep deprivation and caffeine were inversely associated.

Taken together, these findings demonstrate that in those subjects in whom prolonged wakefulness-induced the largest increase in a fronto-occipital power ratio in the sleep and waking EEG, caffeine most potently reduced this ratio. Moreover, caffeine modified the EEG in state-specific manner in those frequencies, which most reliably reflect the functional consequences of sleep deprivation.

\section{CAFFEINE IMPROVES IMPAIRED NEUROBEHAVIORAL PERFORMANCE AFTER SLEEP DEPRIVATION}

Sustained vigilant attention as reliably quantified by performance on the PVT is also highly sensitive to wakefulness-induced impairment (Lim and Dinges, 2008). Optimal response speed on the PVT was recently found to be less impaired after prolonged wakefulness in self-rated caffeine-insensitive individuals than in caffeinesensitive subjects (Rétey et al., 2006). Also this difference was reliably counteracted by caffeine, and the effects of sleep deprivation and caffeine were inversely associated. Because the interaction of caffeine with circadian aspects of waking performance is minor (Wyatt et al., 2004), this study strongly suggested that adenosinergic mechanisms contribute to waking-induced impairment of neurobehavioral functions. Based on this evidence, we hypothesized that increased age not only affects the susceptibility to sleep deprivation, but also the response to the stimulant effects of caffeine.

\section{ADVANCED AGE ALTERS FUNCTIONAL ASPECTS OF THE ADENOSINERGIC SYSTEM}

The striking age-related reductions in SWS/SWA may reflect an age-related decline in the build-up of homeostatic sleep pressure (or sleep need) during wakefulness, a lower efficiency in dissipating sleep pressure during sleep, or an altered interplay of homeostatic and circadian aspects of sleep-wake regulation. The currently available evidence does not provide unequivocal support for an exclusive one of these possibilities (Dijk et al., 1989, 1999, 2010; Landolt et al., 1996; Buysse et al., 2005; Cajochen et al., 2006; Münch et al., 2007). With respect to adenosine, microdialysis studies in rat basal forebrain revealed that extra-cellular adenosine levels were higher in old animals (21.5 months) when compared to young animals (3.5 months) in baseline and throughout sleep deprivation (Murillo-Rodriguez et al., 2004). Given the more superficial sleep in old rats and the suggested role for adenosine 
in promoting SWS/SWA, these data indicated that the sensitivity of adenosine receptors declines with increasing age. In support of this hypothesis, autoradiography in rat brain slices and PET with ${ }^{18} \mathrm{~F}$-CPFPX in humans showed that adenosine $\mathrm{A}_{1}$ receptor binding was significantly reduced with age in many cortical and subcortical brain regions (Meerlo et al., 2004; Meyer et al., 2007). No such studies were performed to date to investigate age-related changes in functional aspects of $\mathrm{A}_{2 \mathrm{~A}}$ receptors in the brain.

In conclusion, the available literature indicates that sleep homeostasis is functional in older individuals, yet impaired adenosine receptor-mediated signal transduction may lead to reduced SWS/SWA at night, lower daytime sleep propensity, and reduced vulnerability to the neurobehavioral consequences of sleep deprivation.

\section{ADVANCED AGE MODULATES THE EFFECTS OF CAFFEINE ON THE SLEEP EEG}

Drapeau et al. (2006) investigated age-related changes in the acute effects of caffeine on sleep and the sleep EEG at night. They found that intake of $2 \times 100 \mathrm{mg}$ caffeine within $3 \mathrm{~h}$ prior to bedtime similarly lengthened sleep latency, reduced sleep efficiency, and shortened sleep duration in healthy middle-aged (mean age: $50.3 \pm 1.6$ years; $n=12)$ and young $(23.8 \pm 0.7$ years; $n=12)$ adults. Moreover, caffeine reduced $\sim 1-4 \mathrm{~Hz}$ activity above frontal, central, and parietal brain areas, and increased high-frequency power (many bins within $15-32 \mathrm{~Hz}$ ) in frontal and central EEG derivations in both age groups. Subtle differences in the reduction of low-delta $(<1 \mathrm{~Hz})$ activity in the prefrontal region indicated that the sleep EEG of the older subjects may be more sensitive to the effects of the xanthine. In a follow-up study in 12 middleaged $(53.8 \pm 1.1$ years $)$ and 12 young $(24.2 \pm 1.0$ years $)$ men and women, these authors also investigated the action of $2 \times 100 \mathrm{mg}$ caffeine on daytime recovery sleep after $25 \mathrm{~h}$ of prolonged wakefulness (Carrier et al., 2009). Again, caffeine similarly decreased sleep efficiency, sleep duration, SWS and REM sleep, and reduced EEG synchronization in NREM sleep (reduced 4-12 Hz activity and enhanced $14-19 \mathrm{~Hz}$ activity) in both age groups. Nevertheless, the combined influence of older age and caffeine led to great difficulty in the middle-aged subjects to consolidate sleep during the daytime, at the time of a strong circadian waking signal in the morning and early afternoon.

These experiments indicate that the sleep EEG is slightly more vulnerable to caffeine-induced changes in middle-aged adults when compared to young adults. This observation may challenge the hypothesis of reduced sensitivity of adenosine receptors with increasing age.

\section{ADVANCED AGE ATTENUATES THE EFFICACY OF CAFFEINE TO COUNTERACT THE CONSEQUENCES OF SLEEP DEPRIVATION}

Given the assumption that reduced vulnerability to sleep loss may reflect attenuated adenosine signal transmission, it was hypothesized that the effects of caffeine during prolonged wakefulness would be reduced in older adults when compared to young adults. To test this hypothesis, the build-up of regional EEG theta activity, subjective sleepiness, and performance on the PVT during sleep deprivation was examined in healthy aged and caffeine-insensitive and -sensitive young men. It was predicted that older subjects would respond similarly to caffeine-insensitive subjects to the effects of both sleep deprivation and caffeine.

Inclusion criteria for all three groups were the same with respect to habitual sleep duration $(7-8 \mathrm{~h}$ per night), daytime sleepiness ( $<10$ on Epworth Sleepiness Scale), body-mass-index $\left(20-25 \mathrm{~kg} / \mathrm{m}^{2}\right)$, and habitual consumption of caffeine (one to three caffeinated beverages per day), and alcohol $(<5$ drinks per week). Physical examination confirmed good health in the older men. Before enrollment into the study, low sleep efficiency $(<80 \%)$, sleep apnea (apnea/hypopnea index $>5)$, and nocturnal myoclonus ( $>5$ periodic limb movements per hour of sleep) were excluded by polysomnography in the laboratory. No study participant had a history of neurologic or psychiatric disease. All subjects were non-smokers and denied taking any medication or consuming illicit drugs. They refrained from caffeine for 2 weeks prior to the study. They were also requested to abstain from ethanol and to maintain regular 8:16-h sleep-wake cycles for 5 days prior to the experiment. According to the reported habitual sleep times, sleep was scheduled from 23:00 to 07:00 (four young men, all older men) or from 24:00 to 08:00 (18 young men). Deviation of more than $1 \mathrm{~h}$ from these schedules was not allowed. Compliance with the pre-study instructions was verified by inspecting the records from activity monitors worn on the wrist of the non-dominant arm, and by determining the level of caffeine in saliva and breath ethanol concentration upon arrival in the sleep laboratory.

Because all experimental details were described in earlier publications (Adam et al., 2006; Rétey et al., 2006, 2007), they are not fully reported here. In brief, all volunteers participated in two blocks of four consecutive nights separated by 1 week. The first and second nights of each block served as adaptation and baseline nights. Then, subjects stayed awake for $40 \mathrm{~h}$ until bedtime of the recovery night. Standardized waking EEG recordings, administration of the Stanford Sleepiness Scale, and testing of PVT performance occurred at 3-h intervals throughout prolonged wakefulness. Two doses of $200 \mathrm{mg}$ caffeine and placebo in the form of capsules were administered after 11 and $23 \mathrm{~h}$ of extended wakefulness (randomized, double-blind, cross-over design). During sleep deprivation, the subjects remained under continuous supervision of members of the research team. They were allowed to read, study, play games, watch films, and occasionally take a walk outside the laboratory.

\section{AGED INDIVIDUALS SHOW REDUCED EFFECTS OF SLEEP DEPRIVATION AND CAFFEINE ON FRONTAL EEG THETA ACTIVITY}

First, the effects of prolonged wakefulness on regional theta power in the waking EEG were quantified in the placebo condition. Averaged activity in the $6.25-$ to $8.25-\mathrm{Hz}$ band recorded at 11:00, 14:00, and 17:00 after the night without sleep was expressed as a percentage of the corresponding value in baseline (Rétey et al., 2006). In all three groups, sleep deprivation increased theta activity in fronto-central (FC) and parieto-occipital (PO) derivations (Figure 2). Nevertheless, the repercussions of sleep loss differed among aged, insensitive and sensitive individuals, and between FC and $\mathrm{PO}$ derivations. In particular, the increase in FC was significantly reduced in older men when compared to caffeine-sensitive young subjects. 


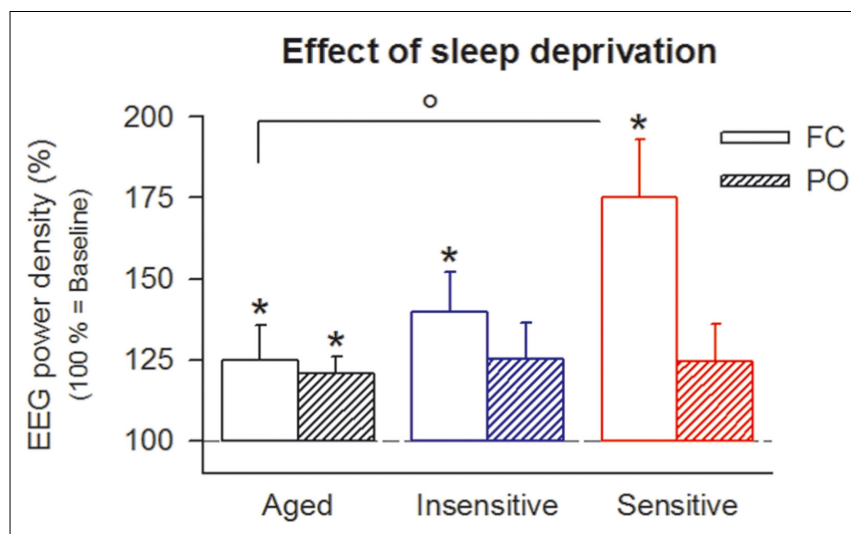

Effect of caffeine

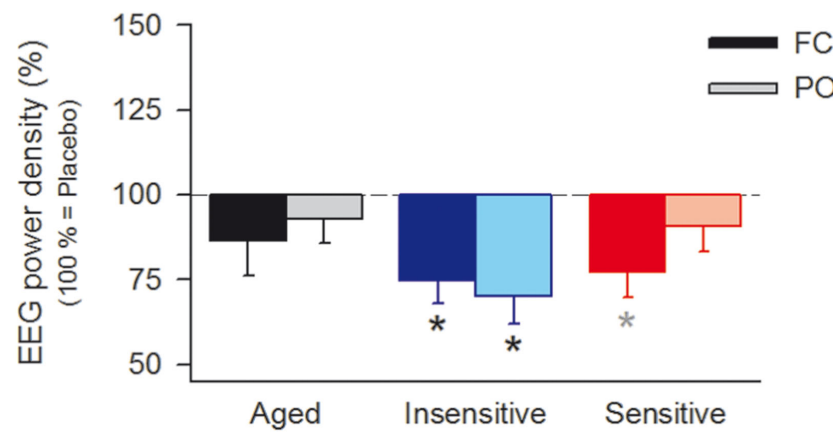

FIGURE 2 | Effects of sleep deprivation and caffeine on theta power $(6.25-8.25 \mathrm{~Hz}$ ) in the waking EEG (eyes open) in fronto-central (FC, open bars) and parieto-occipital (PO, striped bars) derivations in aged ( $n=10$, black bars) and caffeine-insensitive ( $n=10$, blue bars) and -sensitive ( $n=12$, red bars) young men. Upper panel: to quantify the effect of sleep deprivation, theta activity after sleep deprivation in the placebo condition was expressed as a percentage of the corresponding baseline value. Data represent means \pm SEM. Three-way mixed-model ANOVA with the factors "group" (age, insensitive, sensitive), "deprivation" (sleep deprivation, baseline), and "derivation" (FC, PO) revealed significant main effects of "deprivation" $\left(F_{1,66.1}=19.8, p<0.001\right)$ and "derivation" $\left(F_{1,48.8}=4.8, p<0.04\right)$, as well as a significant "group" $\times$ "derivation" interaction $\left(F_{1,48.8}=5.2, p<0.009\right)$. ${ }^{*} p<0.04$ (two-tailed, paired $t$-tests), ${ }^{\circ} p<0.04$ (two-tailed, unpaired $t$-tests). Lower panel: to quantify the effect of caffeine, theta activity after sleep deprivation in the caffeine condition was expressed as a percentage of the corresponding value in the placebo condition. Data represent means \pm SEM. Three-way mixed-model ANOVA with the factors "group," "treatment" (caffeine, placebo), and "derivation" revealed a significant main effect of "treatment" $\left(F_{1,36.5}=26.8, p<0.001\right)$, as well as a significant "group" $\times$ "derivation" interaction $\left(F_{1,28.6}=4.8\right.$, $p<0.02) .{ }^{*} p<0.04,{ }^{*} p<0.07$ (two-tailed, paired t-tests).

Caffeine attenuated the sleep deprivation-induced increase in theta activity in the waking EEG (Figure 2). When all three groups were considered, the reduction was more pronounced in the FC derivation and only significant in young subjects, especially in the caffeine-insensitive group. Regression analyses revealed an inverse relation between the effects of sleep deprivation and caffeine on the $\mathrm{FC} / \mathrm{PO}$ ratio in theta power (Figure 3). This finding indicates that in those subjects in whom sleep deprivation-induced the largest increase in the FC/PO gradient in EEG theta activity, caffeine most potently reduced this gradient.

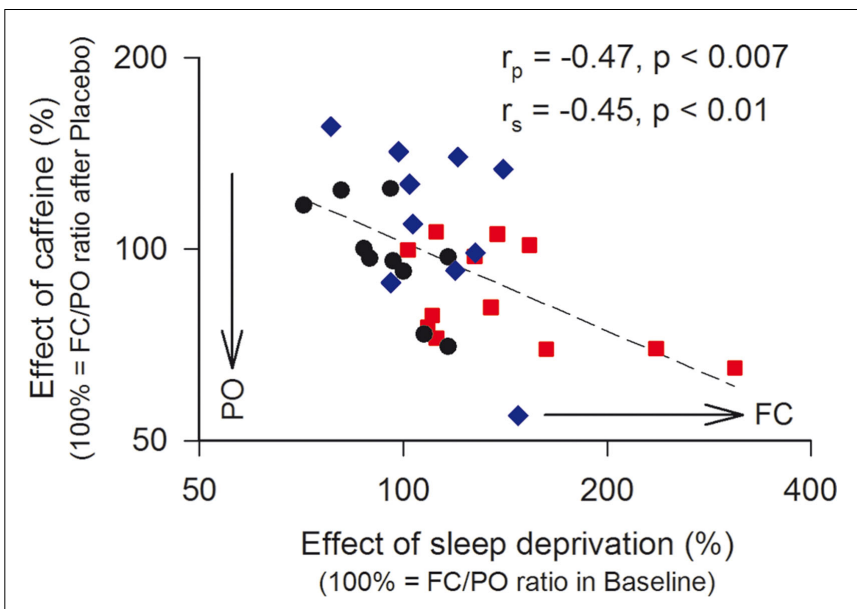

FIGURE 3 | Relationship between the effects of sleep deprivation and caffeine on FC/PO power ratios in the 6.25- to 8.25- $\mathrm{Hz}$ band of the waking EEG. To quantify the effect of sleep deprivation, the FC/PO ratio after sleep deprivation in the placebo condition was expressed as a percentage of the corresponding baseline value. To quantify the effect of caffeine, the FC/PO ratio after sleep deprivation in the caffeine condition was expressed as a percentage of the corresponding value in the placebo condition. Values above $100 \%$ indicate a shift of power in anterior direction (toward FC), whereas values below $100 \%$ indicate a shift of power in posterior direction (toward PO). Data are plotted on a double-logarithmic scale. Black dots: aged individuals; blue diamonds: caffeine-insensitive individuals; red squares: caffeine-sensitive individuals. A regression line was fitted through 32 individual data points. $r_{\mathrm{p}}$ : Pearson's product-moment correlation coefficient, $r_{\mathrm{s}}$ : Spearman rank correlation coefficient.

\section{AGED INDIVIDUALS SHOW REDUCED EFFECTS OF SLEEP DEPRIVATION AND CAFFEINE ON NEUROBEHAVIORAL PERFORMANCE}

Next, the evolution of subjective sleepiness and vigilant attention in placebo and caffeine conditions were quantified at 3-h intervals throughout sleep deprivation. Aged, as well as caffeine-insensitive and -sensitive young subjects maintained stable performance across the first 16-18 h of prolonged wakefulness (Figure 4). Afterward, sleepiness and lapses on the PVT increased, whereas slowest and fastest reaction times on the PVT decreased. The subjective and objective measures of vigilance in all three groups were worst in the placebo condition in the test sessions occurring between 24 and $32 \mathrm{~h}$ of prolonged wakefulness. The magnitude of impairment, however, differed in all variables. In general, young volunteers who reported high caffeine sensitivity were more impaired by sleep deprivation than aged and caffeine-insensitive young subjects.

Double-blind administration of caffeine improved subjective sleepiness in aged, insensitive, and sensitive men (Figure 4). By contrast, the stimulant attenuated the sleep loss-induced impairment in vigilant attention in caffeine-sensitive subjects only. Previous analyses revealed a significant negative correlation between the effects of sleep deprivation and caffeine on optimal PVT performance in young adults (Rétey et al., 2006). We investigated whether this relationship is also present when the older age group is included. To quantify the effect of caffeine on neurobehavioral performance, optimal PVT speed in the caffeine condition at 11:00, 14:00, and 17:00 after sleep deprivation was compared 


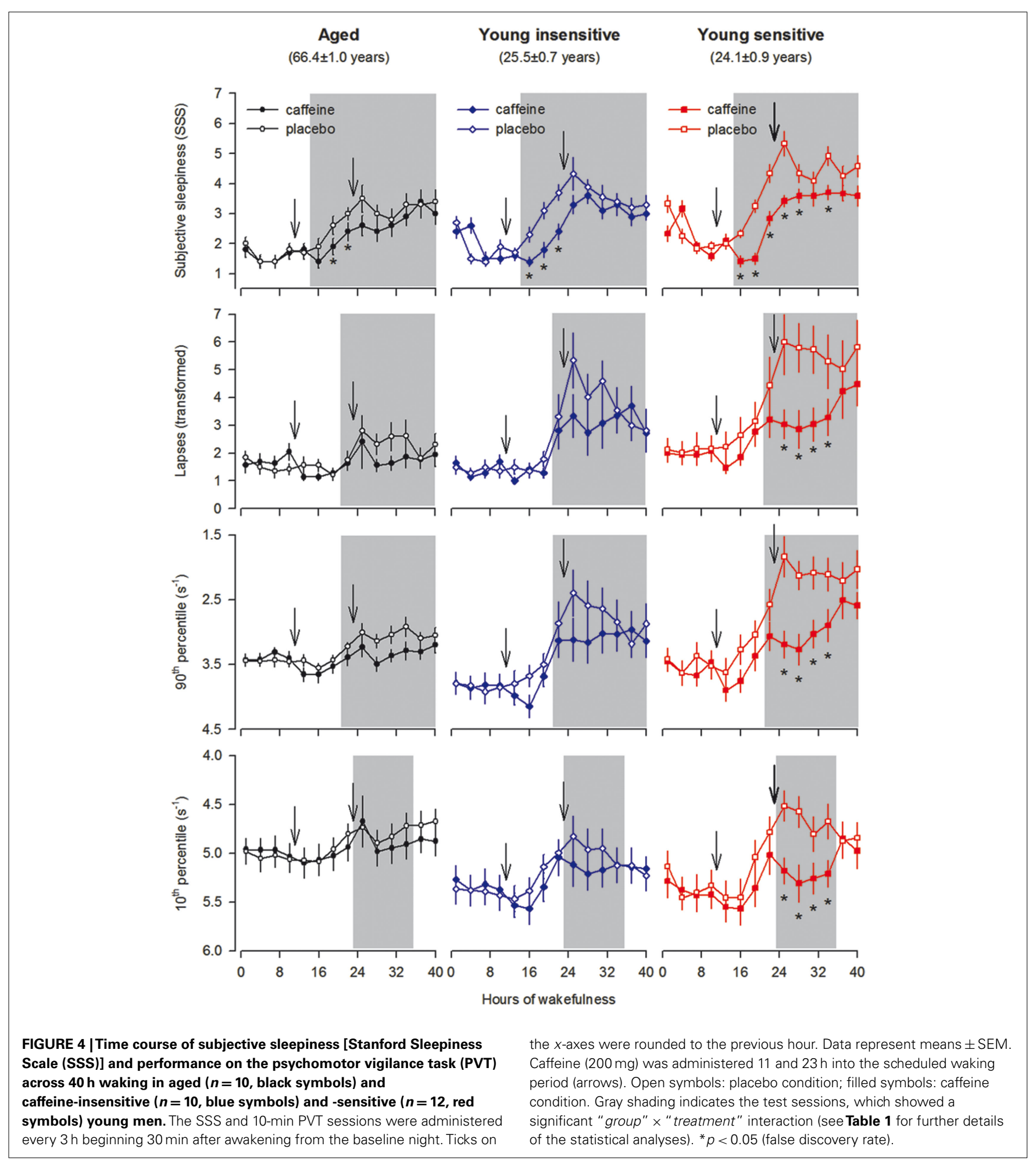

to the corresponding value in the placebo condition. Indeed, a significant negative association between the effects of sleep deprivation and caffeine was found (Figure 5). In other words, including young and older individuals, those subjects with the largest impairment from sleep loss showed the largest benefit from caffeine.

\section{NO DIFFERENCE IN CAFFEINE PHARMACOKINETICS IN AGED, INSENSITIVE, AND SENSITIVE INDIVIDUALS}

There exist large inter-individual differences in caffeine metabolism in the liver that may be modified by age (Tanaka, 1998; Rasmussen et al., 2002; Carrier et al., 2009). Therefore, it was determined whether the different effects of caffeine on EEG and 
Table 1 | Statistical analyses of subjective sleepiness and sustained vigilant attention across $40 \mathrm{~h}$ prolonged wakefulness.

\begin{tabular}{|c|c|c|c|c|c|c|c|}
\hline Factors & $\begin{array}{l}\text { "Group" } \\
(F ; p)\end{array}$ & $\begin{array}{l}\text { "Session" } \\
(F ; p)\end{array}$ & $\begin{array}{l}\text { "Treatment" } \\
(F ; p)\end{array}$ & $\begin{array}{l}\text { "Group" } x \\
\text { "session" }(F ; p)\end{array}$ & $\begin{array}{l}\text { "Session"x } \\
\text { "treatment" }(F ; p)\end{array}$ & $\begin{array}{l}\text { "Group" x } \\
\text { "treatment" }(F ; p)\end{array}$ & $\begin{array}{l}\text { "Group" x "session"x } \\
\text { "treatment" }(F ; p)\end{array}$ \\
\hline SSS & $17.1 ; 0.000$ & $57.9 ; 0.000$ & $102.1 ; 0.000$ & $2.5 ; 0.000$ & $2.6 ; 0.002$ & $2.2 ; 0.138$ & $0.7 ; 0.902$ \\
\hline Lapses & $5.8 ; 0.009$ & $17.0 ; 0.000$ & $35.4 ; 0.000$ & $2.4 ; 0.000$ & $3.2 ; 0.002$ & $8.4 ; 0.000$ & $0.5 ; 0.973$ \\
\hline Slowest & $2.3 ; 0.136$ & $26.2 ; 0.000$ & $89.6 ; 0.000$ & $2.9 ; 0.000$ & $4.8 ; 0.002$ & $12.3 ; 0.000$ & $0.9 ; 0.556$ \\
\hline Fastest & $1.4 ; 0.267$ & $21.1 ; 0.000$ & $36.8 ; 0.000$ & $1.7 ; 0.026$ & $3.0 ; 0.001$ & $10.4 ; 0.000$ & $1.3 ; 0.174$ \\
\hline
\end{tabular}

To estimate the effects of sleep deprivation and caffeine, mixed-model ANOVA containing the random-effects factor "subject" and the fixed-effects factors "group" (aged, insensitive, sensitive), "session" (test sessions 1-14), and "treatment" (placebo, caffeine) were performed. The F-and p-values of the fixed-effects factors are reported; the reported p-values were controlled for the false discovery rate. Significant p-values are highlighted by gray shading. SSS, Stanford Sleepiness Scale. PVT, psychomotor vigilance task. Lapses $=$ number of trials with a reaction time (RT) of longer than $500 \mathrm{~ms}$. Slowest $=$ slowest 10 th percentile of RTs. Fastest $=$ fastest 10th percentile of RTs.

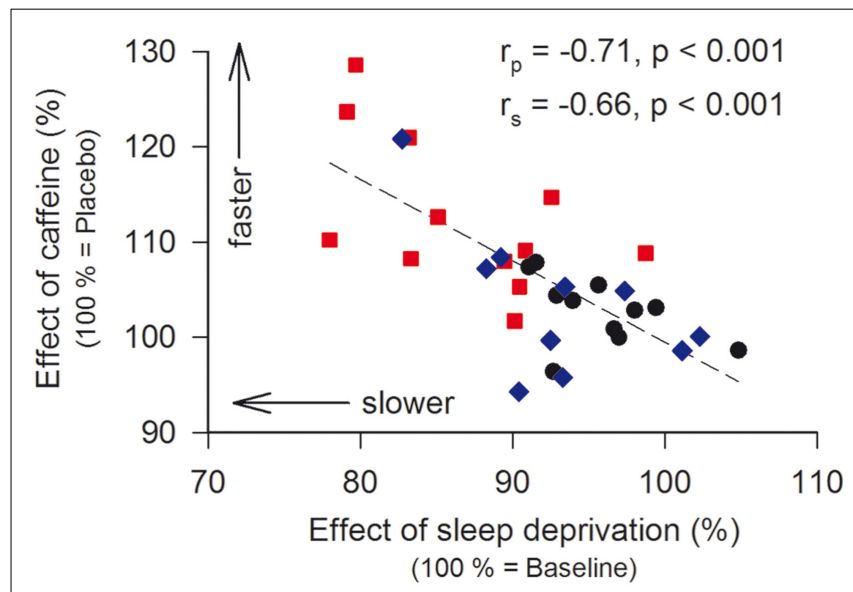

FIGURE 5 | Relationship between the effects of sleep deprivation and caffeine on the 10th percentile of speed (optimal performance) on the psychomotor vigilance task (PVT). To quantify the effect of sleep deprivation, the 10th percentile after sleep deprivation in the placebo condition was expressed as a percentage of the corresponding baseline value. To quantify the effect of caffeine, the 10th percentile after sleep deprivation in the caffeine condition was expressed as a percentage of the corresponding value in the placebo condition. Data are plotted on a linear scale. Black dots: aged individuals; blue diamonds: caffeine-insensitive individuals; red squares: caffeine-sensitive individuals. A linear regression line was fitted through 32 individual data points. $r_{\mathrm{p}}$ : Pearson's product-moment correlation coefficient, $r_{\mathrm{s}}$ : Spearman rank correlation coefficient.

sustained attention reflected different caffeine levels in saliva. One hour after the second dose of caffeine, the concentration in saliva equaled roughly $16-20 \mu \mathrm{mol} / \mathrm{l}$ (aged: $19.8 \pm 1.1 \mu \mathrm{mol} / \mathrm{l}$; insensitive: $15.7 \pm 2.7 \mu \mathrm{mol} / \mathrm{l}$; sensitive: $16.4 \pm 2.5 \mu \mathrm{mol} / \mathrm{l})$. Afterward, the drug levels declined at a similar rate in all groups and reached almost zero at the end of sleep deprivation (Figure 6).

\section{WHICH MECHANISMS MAY UNDERLIE REDUCED AGE-RELATED SENSITIVITY OF THE ADENOSINERGIC SYSTEM?}

The competitive $A_{1}$ and $A_{2 A}$ receptor antagonist, caffeine, "replaces" endogenous adenosine in dose-dependent manner

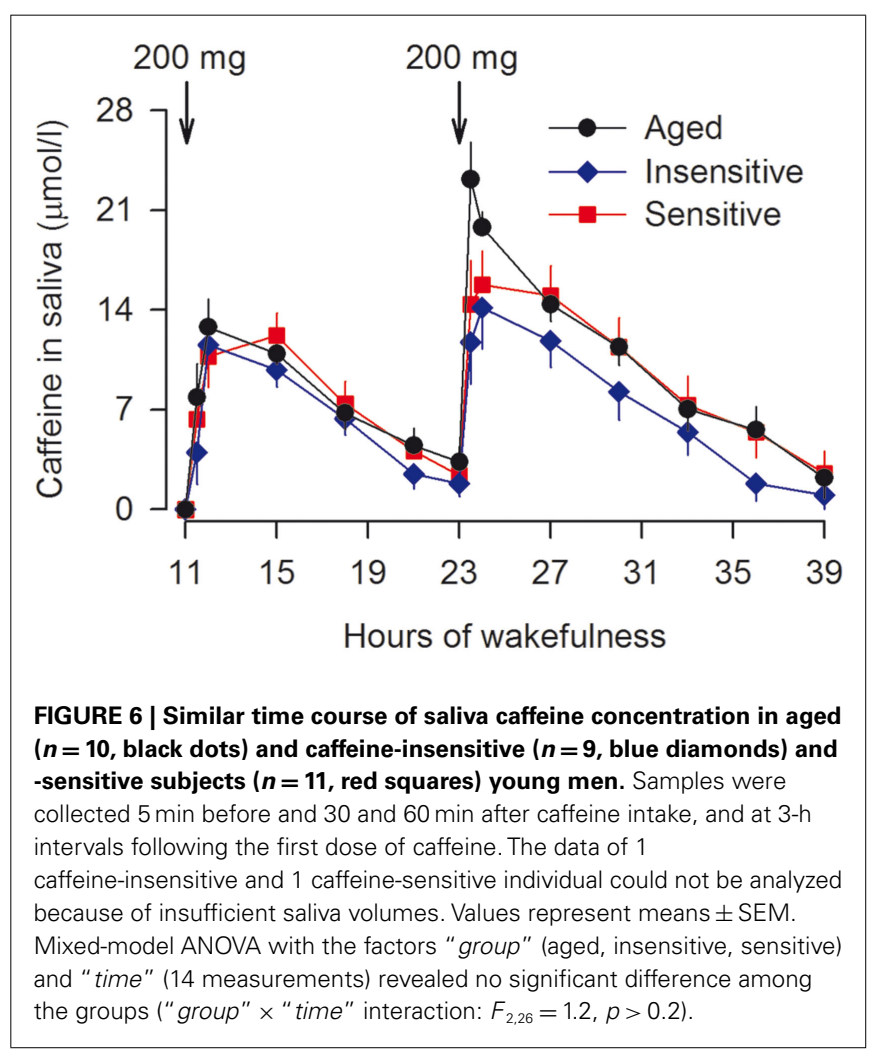

(Fredholm, 1995). Microdialysis studies in rats provided inconsistent results to the question whether extra-cellular adenosine in basal forebrain is differently affected by sleep deprivation in old and young animals (Murillo-Rodriguez et al., 2004; Rytkönen et al., 2010). In humans, the half-life time of caffeine varies widely and differences in habitual caffeine intake may induce physiological adaptations to different cerebral caffeine exposure. The data from carefully controlled studies demonstrate that a fixed dose of caffeine leads to similar saliva concentrations in aged and young individuals who have modest habitual caffeine consumption (Figure 6; see also Carrier et al., 2009). Thus, reduced absorption by the organism is unlikely to underlie the attenuated effects of caffeine on waking EEG and 
neurobehavioral functions after sleep loss. Non-invasive, multimodal imaging techniques may be developed in the future, to simultaneously investigate cerebral adenosine concentrations and distinct adenosine receptor dynamics as a function of exogenous ligand exposure. Such an approach could help to further clarify the exact roles for adenosine and adenosine receptors in age-related changes in individual vulnerability to sleep deprivation.

Pharmaco-genetics provides another powerful avenue in humans to identify molecular mechanisms underlying individual responses to sleep loss. This strategy was successfully employed in young adults to elucidate adenosinergic and dopaminergic mechanisms of sleep-wake regulation (Rétey et al., 2007; Bodenmann and Landolt, 2010; Bodenmann et al., 2012). As a molecular basis contributing to individual caffeine sensitivity, it was found that the distribution of distinct c.1976T $>$ C genotypes (single nucleotide polymorphism rs5751876) of the adenosine $\mathrm{A}_{2 \mathrm{~A}}$ receptor gene (ADORA2A) differed between self-rated caffeine-insensitive and -sensitive people (Rétey et al., 2007). Subsequent, more sophisticated genetic and laboratory studies in selected individuals showed that common variants of $A D O R A 2 A$ are important determinants of psychomotor vigilance in rested and sleep deprived state (Bodenmann et al., 2012). The same gene variants also modulate the neurobehavioral response to caffeine after sleep loss. More specifically, $2 \times 200 \mathrm{mg}$ caffeine were ineffective to improve sustained attention in carriers of HT4 alleles, while the same dose efficiently improved performance in non-HT4 allele carriers (Figure 7). These findings demonstrate that genetic variation of $A D O R A 2 A$ alters the efficacy of pharmacological blockade of $\mathrm{A}_{2 \mathrm{~A}}$ receptors on neurobehavioral performance in young individuals. Although secondary effects of caffeine cannot be excluded (Yang et al., 2010), we suggest that age-related differences in $A_{2 A}$ receptor function contribute to the observed age-related changes in neurobehavioral performance after sleep loss.

\section{CONCLUSION}

Large inter-individual differences characterize the changes induced by prolonged wakefulness on rhythmic brain activity and neurobehavioral performance in young and older healthy individuals, yet the underlying neurobiological mechanisms are not well understood. Advanced age was recently recognized to importantly modulate individual vulnerability to sleep deprivation. Consistent evidence demonstrated that the consequences of sleep loss on sleep and waking EEG, subjective sleepiness, and different aspect of waking state and performance are attenuated in healthy older individuals. To receive first insights into possible neurobiological underpinnings of these age-related changes in humans, the combined effects of sleep deprivation and caffeine on frontal EEG theta activity and sustained attention were evaluated in healthy older men. The response in this cohort to both challenges of the sleep-wake cycle was similar to that in young individuals who are caffeine-insensitive, and significantly less pronounced than in young caffeine-sensitive individuals. Moreover, the effects of sleep deprivation and caffeine were inversely related. These data provide the first experimental evidence in humans that impaired sensitivity of the adenosinergic system contributes to reduced neurobehavioral consequences of sleep deprivation in older age. Provided that genetic variation of $A D O R A 2 A$ in young adults modulates subjective and objective effects of caffeine in wakefulness and sleep, it should be investigated whether cerebral $A_{2 A}$ receptors undergo functional changes in normal aging. Future research will also have to establish whether similar agerelated changes also exist in higher cognitive processing such as working memory and other executive functions (Van Dongen

\section{ADORA2A HT4}

\section{ADORA2A non-HT4}

Clock time

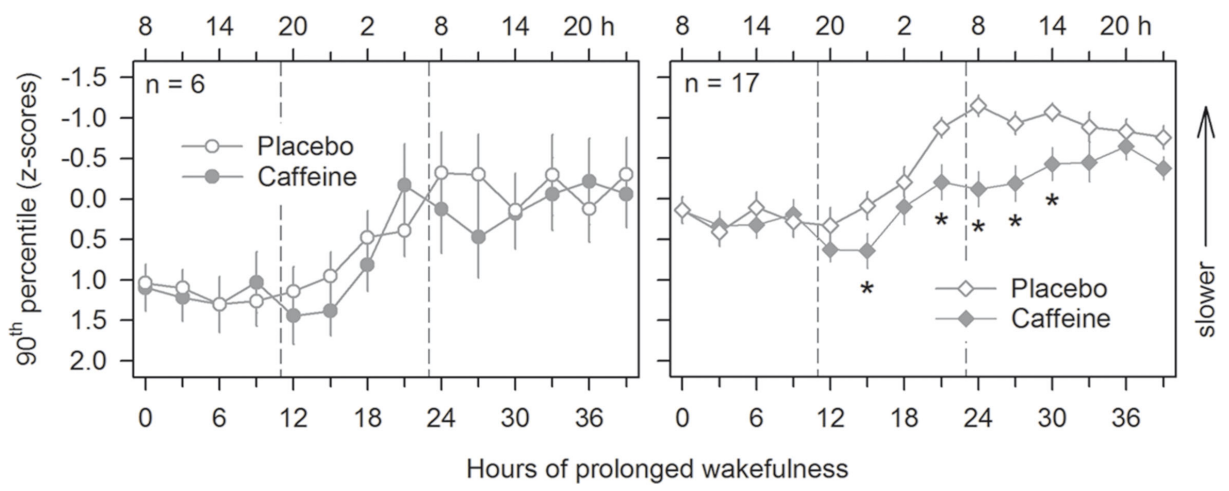

FIGURE 7 | Genetic variation of ADORA2A modulates the effects of caffeine on psychomotor vigilance after sleep loss. The psychomotor vigilance task (PVT) was administered at 3-h intervals throughout prolonged wakefulness, beginning 30 min after wake-up from the baseline nights. Mean values ( \pm SEM) of the 10th percentile of reaction times (expressed as speed, 1/reaction time) in young carriers of HT4 (left panels) and non-HT4 haplotype (right panels) alleles of ADORA2A are plotted. Ticks on the $x$-axes were rounded to the previous hour. Compared to placebo (open symbols), $2 \times 200 \mathrm{mg}$ caffeine (filled symbols) improved optimal PVT speed after sleep loss in non-HT4 haplotype carriers only (ANOVA: "haplotype": $F_{1,21.2}=7.91, p<0.02$; "session": $F_{13,205}=13.43, p<0.0001$, "treatment": $F_{1,68}=8.45, p<0.005$; "haplotype" $\times$ "treatment" $\times$

"session": $F_{26,219}=2.1, p<0.003$ ). ${ }^{*} p<0.05$ (caffeine vs. placebo; two-tailed, paired $t$-tests). 
et al., 2004), as well as in performance in ecological situations such as nocturnal driving (Sagaspe et al., 2007). Given the large demographic changes currently occurring in the Western World, this research is of high scientific interest because it will reveal new insights into the normal age-related changes in physiological sleep-wake regulation. In addition, it is also of clinical importance, because it may identify predictors and biomarkers of behavioral and health consequences of shift work, jet lag, and voluntary sleep restriction, which are highly prevalent in the modern " $24 / 7$ " society. Finally, it may lead to the rational development of novel,

\section{REFERENCES}

Adam, M., Rétey, J. V., Khatami, R., and Landolt, H.-P. (2006). Age-related changes in the time course of vigilant attention during 40 hours without sleep in men. Sleep 29, 55-57.

Bachmann, V., Klaus, F., Bodenmann, S., Schäfer, N., Brugger, P., Huber, S., Berger, W., and Landolt, H.P. (2012). Functional ADA polymorphism increases sleep depth and reduces vigilant attention in humans. Cereb. Cortex 22, 962-970.

Bauer, A., and Ishiwata, K. (2009). "Adenosine receptor ligands and PET imaging of the CNS," in Handbook of Experimental Pharmacology, eds C. N. Wilson and S. J. Mustafa (Berlin: Springer-Verlag), 617-642.

Bjorness, T. E., Kelly, C. L., Gao, T. S., Poffenberger, V., and Greene, R. W. (2009). Control and function of the homeostatic sleep response by adenosine $\mathrm{A}(1)$ receptors. J. $\mathrm{Neu}$ rosci. 29, 1267-1276.

Blatter, K., Graw, P., Munch, M., Knoblauch, V., Wirz-Justice, A., and Cajochen, C. (2006). Gender and age differences in psychomotor vigilance performance under differential sleep pressure conditions. Behav. Brain Res. 168, 312-317.

Bliwise, D. L., and Carrier, J. (2012). Sleep and sleep disorders in older adults. Front. Neurol. (in press).

Bodenmann, S., Hohoff, C., Freitag, C., Deckert, J., Rétey, J. V., Bachmann, V., and Landolt, H.-P. (2012). Polymorphisms of ADORA2A modulate psychomotor vigilance and the effects of caffeine on neurobehavioral performance and sleep EEG after sleep deprivation. Br. J. Pharmacol. 165, 1904-1913.

Bodenmann, S., and Landolt, H. P. (2010). Effects of modafinil on the sleep EEG depend on Val158Met genotype of COMT. Sleep 33, 1027-1035.

Bonnet, M. H., and Rosa, R. R. (1987). Sleep and performance in young adults and older normals and insomniacs during acute sleep loss and recovery. Biol. Psychol. 25, 153-172.

Borbély, A. A. (1980). "Sleep: circadian rhythm versus recovery process," in Functional States of the Brain: Their Determinants, eds M. Koukkou, D. Lehmann, and J. Angst (Amsterdam: Elsevier), 151-161.

Borbély, A. A. (1982). A two process model of sleep regulation. Hum. Neurobiol. 1, 195-204.

Buysse, D. J., Monk, T. H., Carrier, J., and Begley, A. (2005). Circadian patterns of sleep, sleepiness, and performance in older and younger adults. Sleep 28, 1365-1376.

Cajochen, C., Foy, R., and Dijk, D. J. (1999). Frontal predominance of a relative increase in sleep delta and theta EEG activity after sleep loss in humans. Sleep Res. Online 2, 65-69.

Cajochen, C., Münch, M., Knoblauch, V., Blatter, K., and Wirz-Justice, A. (2006). Age-related changes in the circadian and homeostatic regulation of human sleep. Chronobiol. Int. 23, 461-474.

Carrier, J., Paquet, J., FernandezBolanos, M., Girouard, L., Roy, J., Selmaoui, B., and Filipini, D. (2009). Effects of caffeine on daytime recovery sleep: a double challenge to the sleep-wake cycle in aging. Sleep Med. 10, 1016-1024.

Christie, M. A., Bolortuya, Y., Chen, L. C., McKenna, J. T., McCarley, R. W., and Strecker, R. E. (2008). Microdialysis elevation of adenosine in the basal forebrain produces vigilance impairments in the rat psychomotor vigilance task. Sleep 31, 1393-1398.

Dijk, D. J., and Archer, S. N. (2010). PERIOD3, circadian phenotypes, and sleep homeostasis. Sleep Med. Rev. 14, 151-160.

Dijk, D. J., Beersma, D. G., and van den Hoofdakker, R. H. (1989). All night spectral analysis of EEG sleep in young adult and middle-aged male subjects. Neurobiol. Aging 10, 677-682.

Dijk, D. J., Duffy, J. F., Riel, E., Shanahan, T. L., and Czeisler, C. A.

effective, and safe countermeasures to reduce sleepiness and behavioral and cognitive impairments as a consequence of insufficient sleep.

\section{ACKNOWLEDGMENTS}

We thank Dr. R. Khatami, MD, for the medical examination of the aged study participants. The authors' research was supported by the Swiss National Science Foundation grants \# 31-67060.01, 3100A0-107874, and 310000-120377, and the EU Marie Curie grant MCRTN-CT-2004-512362.

(1999). Ageing and the circadian and homeostatic regulation of human sleep during forced desynchrony of rest, melatonin and temperature rhythms. J. Physiol. (Lond.) 516, 611-627.

Dijk, D. J., Groeger, J. A., Stanley, N., and Deacon, S. (2010). Age-related reduction in daytime sleep propensity and nocturnal slow wave sleep. Sleep 33, 211-223.

Drapeau, C., Hamel-Hébert, I., Robillard, R., Selmaoui, B., Filipini, D., and Carrier, J. (2006). Challenging sleep in aging: the effects of 200 $\mathrm{mg}$ of caffeine during the evening in young and middle-aged moderate caffeine consumers. J. Sleep Res. 15, 133-141.

Duffy, J. F., Willson, H. J., Wang, W., and Czeisler, C. A. (2009). Healthy older adults better tolerate sleep deprivation than young adults. J. Am. Geriatr. Soc. 57, 1245-1251.

Elmenhorst, D., Basheer, R., McCarley, R. W., and Bauer, A. (2009). Sleep deprivation increases $\mathrm{A}(1)$ adenosine receptor density in the rat brain. Brain Res. 1258 , 53-58.

Elmenhorst, D., Meyer, P. T., Winz, O. H., Matusch, A., Ermert, J., Coenen, H. H., Basheer, R., Haas, H. L., Zilles, K., and Bauer, A. (2007). Sleep deprivation increases $\mathrm{A}(1)$ adenosine receptor binding in the human brain: a positron emission tomography study. J. Neurosci. 27, 2410-2415.

Fredholm, B. B. (1995). Adenosine adenosine receptor and the action of caffeine. Pharmacol. Toxicol. 76, 93-101.

Fredholm, B. B., Chen, J. F., Cunha, R. A., Svenningsson, P., and Vaugeois, J. M. (2005). Adenosine and brain function. Int. Rev. Neurobiol. 63, 191-270.

Gallopin, T., Luppi, P. H., Cauli, B., Urade, Y., Rossier, J., Hayaishi, O., Lambolez, B., and Fort, P. (2005). The endogenous somnogen adenosine excites a subset of sleep-promoting neurons via A2a receptors in the ventrolateral preoptic nucleus. Neuroscience 134, 1377-1390.

Goel, N., Rao, H., Durmer, J. S., and Dinges, D. F. (2009). Neurocognitive consequences of sleep deprivation. Semin. Neurol. 29, 320-339.

Halassa, M. M., Florian, C., Fellin, T., Munoz, J. R., Lee, S. Y., Abel, T., Haydon, P. G., and Frank, M. G. (2009). Astrocytic modulation of sleep homeostasis and cognitive consequences of sleep loss. Neuron 61 , 213-219.

Hasan, S., Dauvilliers, Y., Mongrain, V., Franken, P., and Tafti, M. (2012). Age-related changes in sleep in inbred mice are genotype dependent. Neurobiol. Aging 33, 195.e13195.e26.

Hayaishi, O., Urade, Y., Eguchi, N., and Huang, Z.-L. (2004). Genes for prostaglandin D synthase and receptor as well as adenosine $\mathrm{A} 2 \mathrm{a}$ receptor are involved in the homeostatic regulation of NREM sleep. Arch. Ital. Biol. 142, 533-539.

Haydon, P. G., and Carmignoto, G. (2006). Astrocyte control of synaptic transmission and neurovascular coupling. Physiol. Rev. 86, 1009-1031.

Huang, Z. L., Qu, W. M., Eguchi, N., Chen, J. F., Schwarzschild, M. A., Fredholm, B. B., Urade, Y., and Hayaishi, O. (2005). Adenosine A2A, but not $A 1$, receptors mediate the arousal effect of caffeine. Nat. Neurosci. 8, 858-859.

Krueger, J. M., Rector, D. M., Roy, S., Van Dongen, H. P. A., Belenky, G., and Panksepp, J. (2008). Sleep as a fundamental property of neuronal assemblies. Nat. Rev. Neurosci. 9, 910-919.

Krueger, J. M., Taishi, P., De, A., Davis, C. J., Winters, B. D., Clinton, J., Szentirmai, E., and Zielinski, M. R. (2010). ATP and the purine type $2 X 7$ receptor affect sleep. J. Appl. Physiol. 109, 1318-1327.

Landolt, H.-P. (2008a). Genotypedependent differences in sleep, vigilance, and response to stimulants. Curr. Pharm. Des. 14, 3396-3407. 
Landolt, H.-P. (2008b). Sleep homeostasis: a role for adenosine in humans? Biochem. Pharmacol. 75, 2070-2079.

Landolt, H.-P., Dijk, D. J., Achermann, P., and Borbély, A. A. (1996). Effect of age on the sleep EEG: slow-wave activity and spindle frequency activity in young and middle-aged men. Brain Res. 738, 205-212.

Landolt, H.-P., Rétey, J. V., Tönz, K., Gottselig, J. M., Khatami, R., Buckelmüller, I., and Achermann, P. (2004). Caffeine attenuates waking and sleep electroencephalographic markers of sleep homeostasis in humans. Neuropsychopharmacology 29, 1933-1939.

Landolt, H.-P., Werth, E., Borbély, A. A., and Dijk, D. J. (1995). Caffeine intake $(200 \mathrm{mg})$ in the morning affects human sleep and EEG power spectra at night. Brain Res. 675, 67-74.

Lim, J. L., and Dinges, D. F. (2008). Sleep deprivation and vigilant attention. Ann. N. Y. Acad. Sci. 1129, 305-322.

Meerlo, P., Roman, V., Farkas, E., Keijser, J. N., Nyakas, C., and Luiten, P. G. M. (2004). Ageing-related decline in adenosine $\mathrm{A} 1$ receptor binding in the rat brain: an autoradiographic study. J. Neurosci. Res. 78, 742-748.

Meyer, P. T., Elmenhorst, D., Boy, C., Winz, O., Matusch, A., Zilles, K., and Bauer, A. (2007). Effect of aging on cerebral A(1) adenosine receptors: a [F-18] CPFPX PET study in humans. Neurobiol. Aging 28, 1914-1924.

Münch, M., Knoblauch, V., Blatter, K., Schröder, C., Schnitzler, C., Kräuchi, K., Wirz-Justice, A., and Cajochen, C. (2004). The frontal predominance in human EEG delta activity after sleep loss decreases with age. Eur. J. Neurosci. 20, 1402-1410.

Münch, M., Knoblauch, V., Blatter, K., Wirz-Justice, A., and Cajochen, C. (2007). Is homeostatic sleep regulation under low sleep pressure modified by age? Sleep 30, 781-792.

Murillo-Rodriguez, E., BlancoCenturion, C., Gerashchenko, D., Salin-Pascual, R. J., and Shiromani, P. J. (2004). The diurnal rhythm of adenosine levels in the basal forebrain of young and old rats. Neuroscience 123, 361-370.

Okada, T., Mochizuki, T., Huang, Z. L., Eguchi, N., Sugita, Y., Urade, Y., and Hayaishi, O. (2003). Dominant localization of adenosine deaminase in leptomeninges and involvement of the enzyme in sleep. Biochem. Biophys. Res. Commun. 312, 29-34.

Palchykova, S., Winsky-Sommerer, R., Shen, H. Y., Boison, D., Gerling, A., and Tobler, I. (2010). Manipulation of adenosine kinase affects sleep regulation in mice. J. Neurosci. 30, 13157-13165.

Pascual, O., Casper, K. B., Kubera, C., Zhang, J., Revilla-Sanchez, R., Sul, J. Y., Takano, H., Moss, S. J., McCarthy, K., and Haydon, P. G. (2005). Astrocytic purinergic signaling coordinates synaptic networks. Science 310 , 113-116.

Philip, P., Taillard, J., Sagaspe, P., Valtat, C., Sanchez-Ortuno, M., Moore, N., Charles, A., and Bioulac, B. (2004). Age, performance and sleep deprivation. J. Sleep Res. 13, 105-110.

Porkka-Heiskanen, T., and Kalinchuk, A. V. (2011). Adenosine, energy metabolism and sleep homeostasis. Sleep Med. Rev. 15, 123-135.

Porkka-Heiskanen, T., Strecker, R. E., and McCarley, R. W. (2000). Brain site-specificity of extracellular adenosine concentration changes during sleep deprivation and spontaneous sleep: an in vivo microdialysis study. Neuroscience 99 507-517.

Rasmussen, B. B., Brix, T. H., Kyvik, K. O., and Brosen, K. (2002). The interindividual differences in the 3-demthylation of caffeine alias CYP1A2 is determined by both genetic and environmental factors. Pharmacogenetics 12, 473-478.

Rétey, J. V., Adam, M., Gottselig, J. M., Khatami, R., Dürr, R., Achermann, P., and Landolt, H.-P. (2006). Adenosinergic mechanisms contribute to individual differences in sleep-deprivation induced changes in neurobehavioral function and brain rhythmic activity. J. Neurosci. 26, 10472-10479.

Rétey, J. V., Adam, M., Khatami, R., Luhmann, U. F. O., Jung, H. H., Berger, W., and Landolt, H.-P. (2007). A genetic variation in the adenosine $\mathrm{A}_{2 \mathrm{~A}}$ receptor gene (ADORA2A) contributes to individual sensitivity to caffeine effects on sleep. Clin. Pharmacol. Ther. 81, 692-698.

Rytkönen, K. M., Wigren, H. K., Kostin, A., Porkka-Heiskanen, T., and Kalinchuk, A. V. (2010). Nitric oxide mediated recovery sleep is attenuated with aging. Neurobiol. Aging 31, 2011-2019.
Sagaspe, P., Taillard, J., Chaumet, G., Moore, N., Bioulac, B., and Philip, P. (2007). Aging and nocturnal driving: better with coffee or a nap? A randomized study. Sleep 30, 1808-1813.

Scammell, T. E., Gerashchenko, D. Y., Mochizuki, T., McCarthy, M. T., Estabrooke, I. V., Sears, C. A., Saper, C. B., Urade, Y., and Hayaishi, O. (2001). An adenosine $A_{2 A}$ agonist increases sleep and induces Fos in ventrolateral preoptic neurons. $\mathrm{Neu}$ roscience $107,653-663$.

Schwierin, B., Borbély, A. A., and Tobler, I. (1996). Effects of N6cyclopentyladenosine and caffeine on sleep regulation in the rat. Eur. J. Pharmacol. 300, 163-171.

Sebastiao, A. M., and Ribeiro, J. A. (2009). "Adenosine receptors and the central nervous system," in Handbook of Experimental Pharmacology, eds C. N. Wilson and S. J. Mustafa (Berlin: Springer Verlag), 471-534.

Tanaka, E. (1998). In vivo age-related changes in hepatic drug-oxidizing capacity in humans. J. Clin. Pharm. Ther. 23, 247-255.

Thakkar, M. M., Winston, S., and McCarley, R. W. (2003). Al receptor and adenosinergic homeostatic regulation of sleep-wakefulness: effects of antisense to the $\mathrm{Al}$ receptor in the cholinergic basal forebrain. J. Neurosci. 23, 4278-4287.

Ticho, S. R., and Radulovacki, M. (1991). Role of adenosine in sleep and temperature regulation in the preoptic area of rats. Pharmacol. Biochem. Behav. 40, 33-40.

Tinguely, G., Finelli, L. A., Landolt, H.P., Borbely, A. A., and Achermann, P. (2006). Functional EEG topography in sleep and waking: statedependent and state-independent features. Neuroimage 32, 283-292.

Urrila, A. S., Hakkarainen, A., Heikkinen, S., Vuori, K., Stenberg, D., Hakkinen, A. M., Lundbom, N., and Porkka-Heiskanen, T. (2004). Stimulus-induced brain lactate: effects of aging and prolonged wakefulness. J. Sleep Res. 13, 111-119.

Van Dongen, H. P. A., Baynard, M. D., Maislin, G., and Dinges, D. F. (2004). Systematic interindividual differences in neurobehavioral impairment from sleep loss: evidence of trait-like differential vulnerability. Sleep 27, 423-433.
Van Dongen, H. P. A., Bender, A. M., and Dinges, D. F. (2012). Systematic individual differences in sleep homeostatic and circadian rhythm contributions to neurobehavioral impairment during sleep deprivation. Accid. Anal. Prev. 45S, 11-16.

Werth, E., Dijk, D. J., Achermann, P., and Borbély, A. A. (1996). Dynamics of the sleep EEG after an early evening nap: experimental data and simulations. Am. J. Physiol. 271, R501R510.

Wigren, H. K., Rytkönen, K. M., and Porkka-Heiskanen, T. (2009). Basal forebrain lactate release and promotion of cortical arousal during prolonged waking is attenuated in aging. J. Neurosci. 29, 11698-11707.

Wyatt, J. K., Cajochen, C., Ritz-De Cecco, A., Czeisler, C. A., and Dijk, D. J. (2004). Low-dose repeated caffeine administration for circadian-phasedependent performance degradation during extended wakefulness. Sleep 27, 374-381.

Yang, A., Palmer, A., and de Wit, $\mathrm{H}$. (2010). Genetics of caffeine consumption and responses to caffeine. Psychopharmacology (Berl.) 211, 245-257.

Conflict of Interest Statement: The authors declare that the research was conducted in the absence of any commercial or financial relationships that could be construed as a potential conflict of interest.

Received: 31 January 2012; paperpending published: 19 February 2012; accepted: 02 April 2012; published online: 27 April 2012.

Citation: Landolt H-P, Rétey JV and Adam M (2012) Reduced neurobehavioral impairment from sleep deprivation in older adults: contribution of adenosinergic mechanisms. Front. Neur. 3:62. doi: 10.3389/fneur.2012.00062

This article was submitted to Frontiers in Sleep and Chronobiology, a specialty of Frontiers in Neurology.

Copyright (c) 2012 Landolt, Rétey and Adam. This is an open-access article distributed under the terms of the Creative Commons Attribution Non Commercial License, which permits noncommercial use, distribution, and reproduction in other forums, provided the original authors and source are credited. 